\title{
Contour Tones and Prosodic Structure in Medumba
}

\author{
KATHRYN H. FRANiCH \\ University of Chicago*
}

\section{Introduction}

This paper investigates the phonetics and phonology of contour tones in Medumba, a Grassfields Bantoid language of Cameroon. Not only are contoured syllables shown to be longer in duration than level syllables of all shapes, but the distributions of phonological processes such as High Tone Anticipation (HTA) and sentence initial downdrift are sensitive to the relative positions in which contoured and level syllables appear. Evidence reveals that variation in the application of HTA and downdrift can be attributed to differences in the prosodic positions in which contoured and level syllables occur. Specifically, contoured syllables are preferred in prominent positions over their level-toned counterparts both at the level of the foot and at the level of the intonational phrase.

Two possible explanations are considered for the above facts. The first is a tonal prominence account similar to de Lacy (2002) whereby contour tones associate to strong positions due to the inherent prominence associated with their tonal properties. The second is a weight-based account whereby contour tones associate to heavy syllables, which are in turn attracted to prominent positions. Though Medumba does not display a general distinction in vowel length, evidence from some loanwords which can be produced with variable vowel length (and which display concomitant variation in prosodic behavior) supports a weightbased account. An analysis of prominence asymmetries between contoured (heavy) and level (light) syllables is provided within the framework of Optimality Theory (Prince \& Smolensky 1993).

\section{Overview of Tone and Contour Formation in Medumba}

Medumba has been analyzed as a 2-level tone system with underlying $\mathrm{H}$ and L tones (Voorhoeve 1971). The language also exhibits extensive downstep and downdrift behavior. Phonetic patterns of downdrift, whereby a $\mathrm{H}$ tone is produced at a lower pitch level than a preceding $\mathrm{H}$ tone when an overt L tone intervenes, are consistent with what Stewart (1965) referred to as 'automatic downstep'. This process is arguably analogous to (nonautomatic) downstep, or the lowering effect found on the second of two $\mathrm{H}$ tones which are separated by a floating L tone. I therefore represent both processes in the same way $\left({ }^{\downarrow}\right)$ for the sake of simpler exposition $^{1}$.

\footnotetext{
*Enormous thanks to Ariane Ngabeu, Junie Djamen and Jean René Djobia for sharing their knowledge of Medumba with me, to Eric Raimy, Draga Zec, and audiences at CUNY Conference on Weight in Phonetics and Phonology, to Alan Yu and members of the University of Chicago Phonology Lab, and to Larry Hyman and audience members of BLS 40 for very useful comments on this research.

${ }^{1}$ See Genzel \& Kügler (2011) for phonetic evidence from Akan (a language with a similar tone system to Medumba) that the lowering effect of nonautomatic and automatic downstep is identical, suggesting that
} 
In addition to level $\mathrm{H}$ and $\mathrm{L}$ tones, Medumba exhibits both falling and rising contours (1). Due to the relatively free occurrence of contour tones on all syllable types in the language, Zhang (2002) categorizes Medumba as one of the least restricted contour tone systems crosslinguistically.

$\begin{array}{lllll} & \text { HL } & & \text { LH } & \\ \text { CVN } & \text { bên } & \text { Relativizer } & \text { lěn } & \text { 'know' } \\ \text { CVO } & \text { ndâp } & \text { 'hit' (consecutive form) } & \text { lăp } & \text { 'hit' } \\ \text { CV } & \text { bô } & \text { Habitual } & \text { kǒ } & \text { 'like / love / want' }\end{array}$

Since the work of Pike (1948) and based on subsequent work by Yip (1989) and many others, phonologists have subscribed to the notion that contour tones in African languages are not unitary entities (as they have been argued to be in a number of East Asian languages), but are rather comprised of sequences of level tones. Evidence for this kind of analysis comes from parallelisms between sequences of level tones on disyllabic words and contours on monosyllabic words. In Medumba, alternations between monosyllabic and disyllabic forms of the same root are found in which a melody of L.H (or H.L) distributed across two syllables is condensed into a contour once the second root syllable dropped. In (2), the verbs làbó 'hit' and nèná 'go' are shown occurring in their disyllabic forms sentence-finally (2a,c), and in their obligatory monosyllabic form sentence-internally ${ }^{2}(2 \mathrm{~b}, \mathrm{~d})$. Once again, raised arrows $\left({ }^{\downarrow}\right)$ represent downstep and downdrift.

(2) Alternating Verb Roots in Disyllabic L.H and Monosyllabic LH Form
a. má là̀bá
1SG hit
b. má \lăp $\downarrow^{\text {mBú }}$
1SG hit dog
'I have hit it.'
'I have hit the dog.'
c. má nغ̇̀ná
1SG go
'I have gone.'
d. má $\downarrow_{\text {něn }} \downarrow_{\text {ndóná }}$
1SG go market
'I have gone to the market.'

There are a number of verb roots, typically of CV shape, which do not have a disyllabic form, and instead are always produced with a contour. Examples of such verbs are in (3).

(3) Contoured Verbs with No Disyllabic Alternation
a. kǒ 'like / love / want'
b. $\chi \check{\mathrm{u}}$ 'have'
c. pi 'rot'
d. nว̌ 'lie down'

It is likely that these verbs were also once disyllabic, and that their second syllable was lost, leading to the permanent association of two tones to a single syllable. Another domain in which contoured morphemes are plentiful, and where such contours likely originated from

the two processes are best treated as a single phonological process.

${ }^{2}$ Note that where downstep/downdrift is marked before a LH contour $\left({ }^{\downarrow} \check{\mathrm{x}}\right)$, this is meant to indicate that the $\mathrm{H}$ of the contour is lowered. 
the historic loss of syllables and reassociation of stranded tones, is in the tense/aspect system. A list of contoured tense and aspect markers is given in (4).

(4) Tense Markers with Contour Tones

$\begin{array}{lll}\text { nô? } & \text { Distant Past 1 } & \text { (DPST1) } \\ \text { lûu } & \text { Distant Past 2 } & \text { (DPST2) } \\ \text { bô } & \text { Habitual } & \text { (HAB) } \\ \text { t } \int w \check{n} n & \text { Progressive } & \text { (PROG) }\end{array}$

Examples (2b) and (2d), as well as all of the examples in (3) and (4) constitute what will be referred to for the remainder of the paper as lexical contours. One final way in which contour tones can be formed in Medumba is through the association of a floating tone morpheme to a word. For example, the words bàm 'sack' and kò 'lance' are both produced with a low tone in isolation. When used in the possessive construction 'sack of the chief' and 'lance of the chief', however, each word is produced with a LH rising tone (5). Voorhoeve (1971) shows convincingly that this rising tone is the result of the association of the floating $\mathrm{H}$ 'associative morpheme' which docks to the first noun in each phrase to create the possessive construction.

(5) L Tone Nouns in Isolation and in Possessive Constructions

bàm 'belly' băm mvòn 'belly of the chief'

kò 'lance' kǒ mvòn 'lance of the chief'

A number of other floating morphemes exist in Medumba which yield similar morphological contours as in (5) when they dock to a word bearing the opposite tone. Though such contours will be briefly discussed in the conclusion section of this paper, for the most part, the focus will focus on lexical contours. Furthermore, many of the phonological processes to be discussed are evidenced most clearly with HL contours. The discussion of LH contours will thus be quite limited, but warrants further in-depth investigation.

\section{Differences in Phonetics and Phonology for Contoured and Level Syllables}

One of the most notable phonetic properties of contoured syllables in Medumba which sets them apart from their level-toned counterparts is that vowel length is consistently longer for contoured syllables than for level syllables of all syllable types (Figure 1). 
Figure 1: Relative Vowel Duration for Contoured vs. Level Syllables

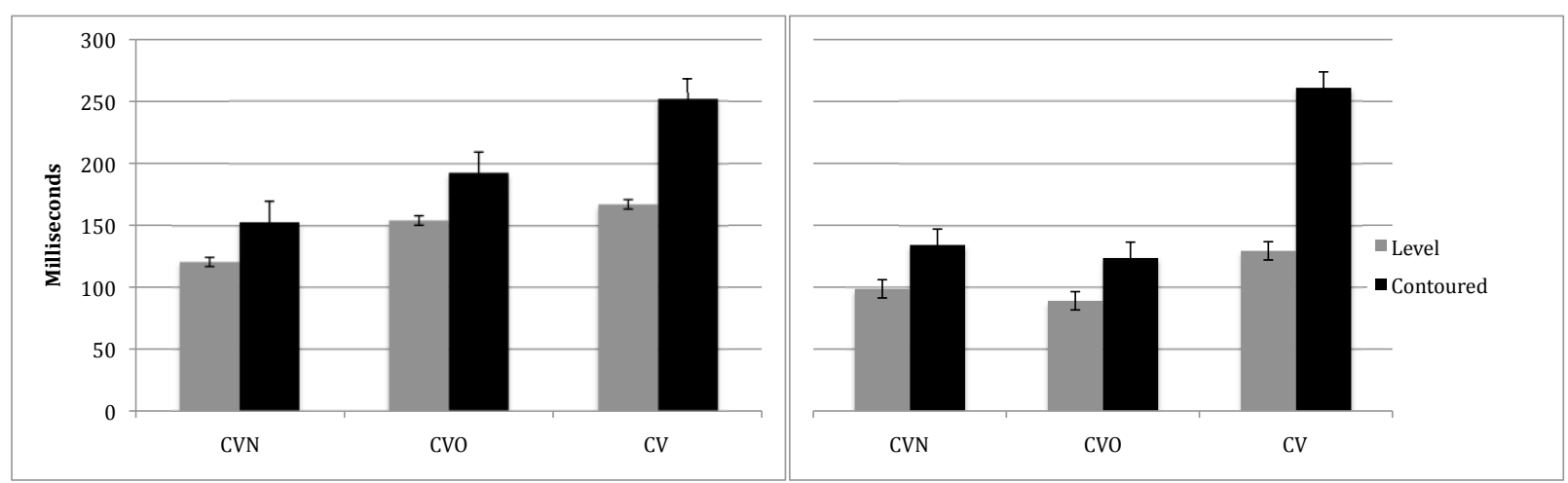

Female Speaker

Male Speaker

This difference in duration is not uncommon: contour tones are often associated with increased duration crosslinguistically, a phenomenon which is thought to be linked to the increased time necessary to both produce perceive $f_{0}$ movement (Zhang 2002, 2004).

In addition to these durational differences, two types of tonal processes in Medumba reflect a difference in the phonological behavior of contoured vs. level syllables: High Tone Anticipation and downdrift. Each will be discussed here in turn.

\subsection{High Tone Anticipation}

High Tone Anticipation occurs in Medumba when the tonal features of a $\mathrm{H}$ tone spread leftward onto those of a preceding L which forms a part of a HL contour (Franich 2013). An illustration of this process is given in (6).

(6) High Tone Anticipation from Question Particle to Verb

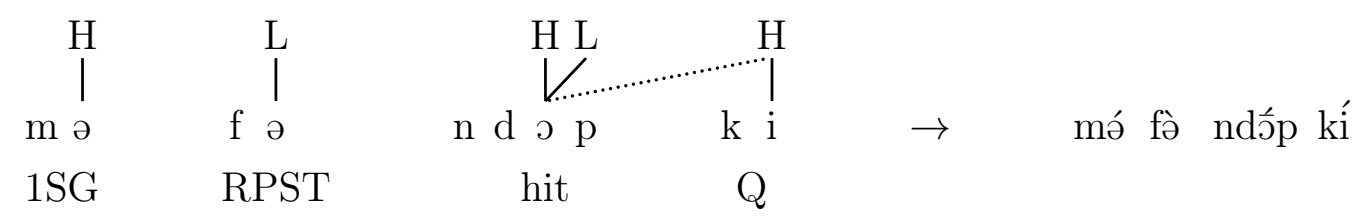

'I hit the dog (yesterday).'

The result of HTA is that the contour on the verb, which is underlyingly HL, is realized as $\mathrm{H}^{\downarrow} \mathrm{H}$, and the $\mathrm{H}$ of the question particle is realized at the same pitch level as the downstepped $\mathrm{H}$ of the contour. To the right of the arrow in (6), we see the $\mathrm{H}^{\downarrow} \mathrm{H}$ contour represented with the acute macron [-] over the vowel of the verb. The question particle is pronounced at the same pitch level as the preceding downstepped $\mathrm{H}$ since the ceiling for $\mathrm{H}$ tones has now been lowered for the remainder of this sentence.

The pitch tracks in Figures 2-4 show how a $\mathrm{H}^{\downarrow} \mathrm{H}$ contour (Figure 2) is realized differently from either a HL contour followed by a ${ }^{\downarrow} \mathrm{H}$ (Figure 3 ) or a HL contour followed by a L and a 
${ }^{\downarrow} \mathrm{H}$ (Figure 4). Relevant portions of the pitch tracks are each enclosed in a dotted rectangle. Notice how the pitch drop in Figure 2 ends roughly at the same level as the following $\mathrm{H}$ tone, whereas those in Figures 3 and 4 drops much lower than the level of the following $\mathrm{H}$ tone.

Figure 2: HTA Results in H to Downstepped H Contour

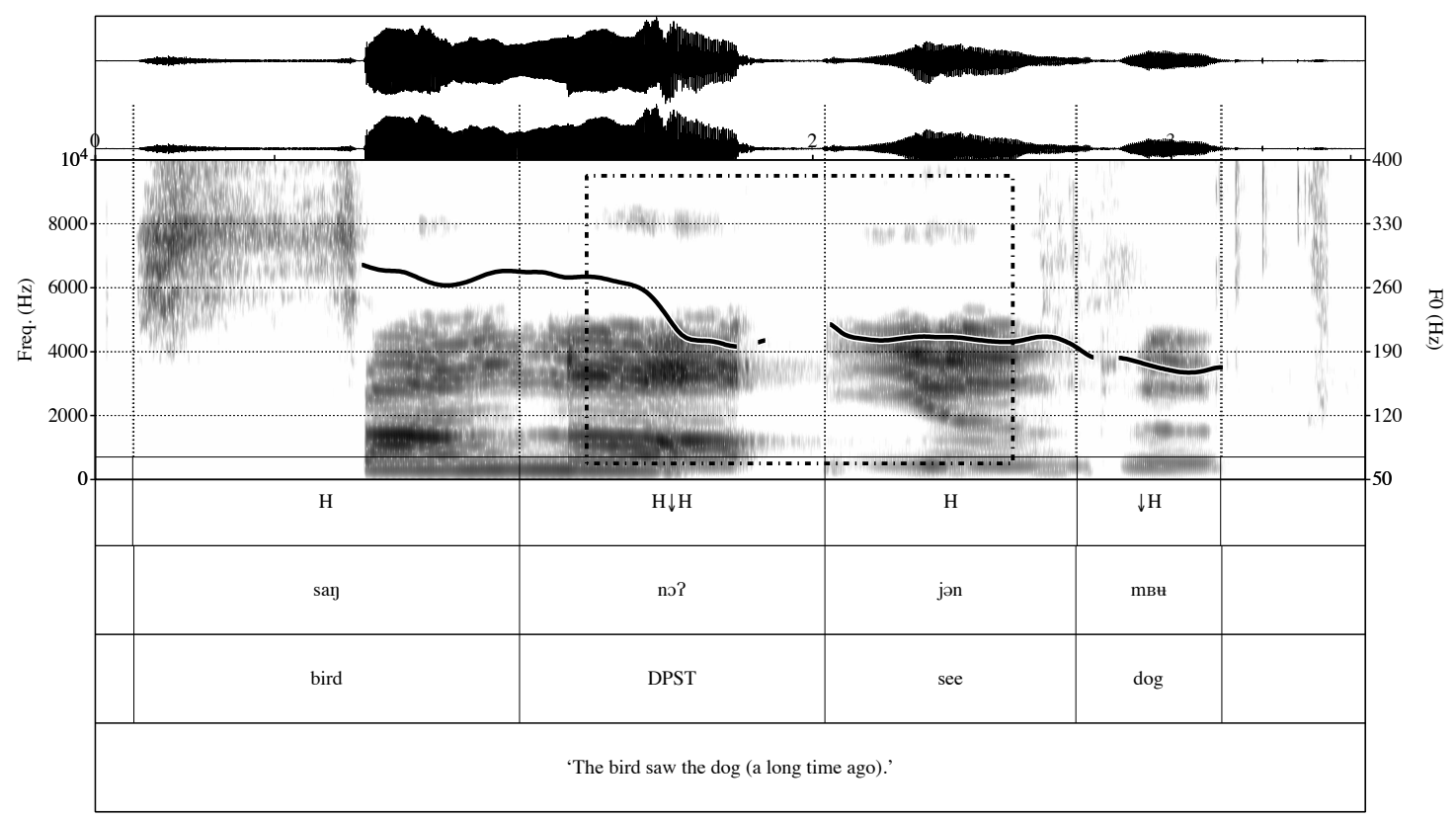


Figure 3: No HTA Results in HL Contour Followed by Downstepped H

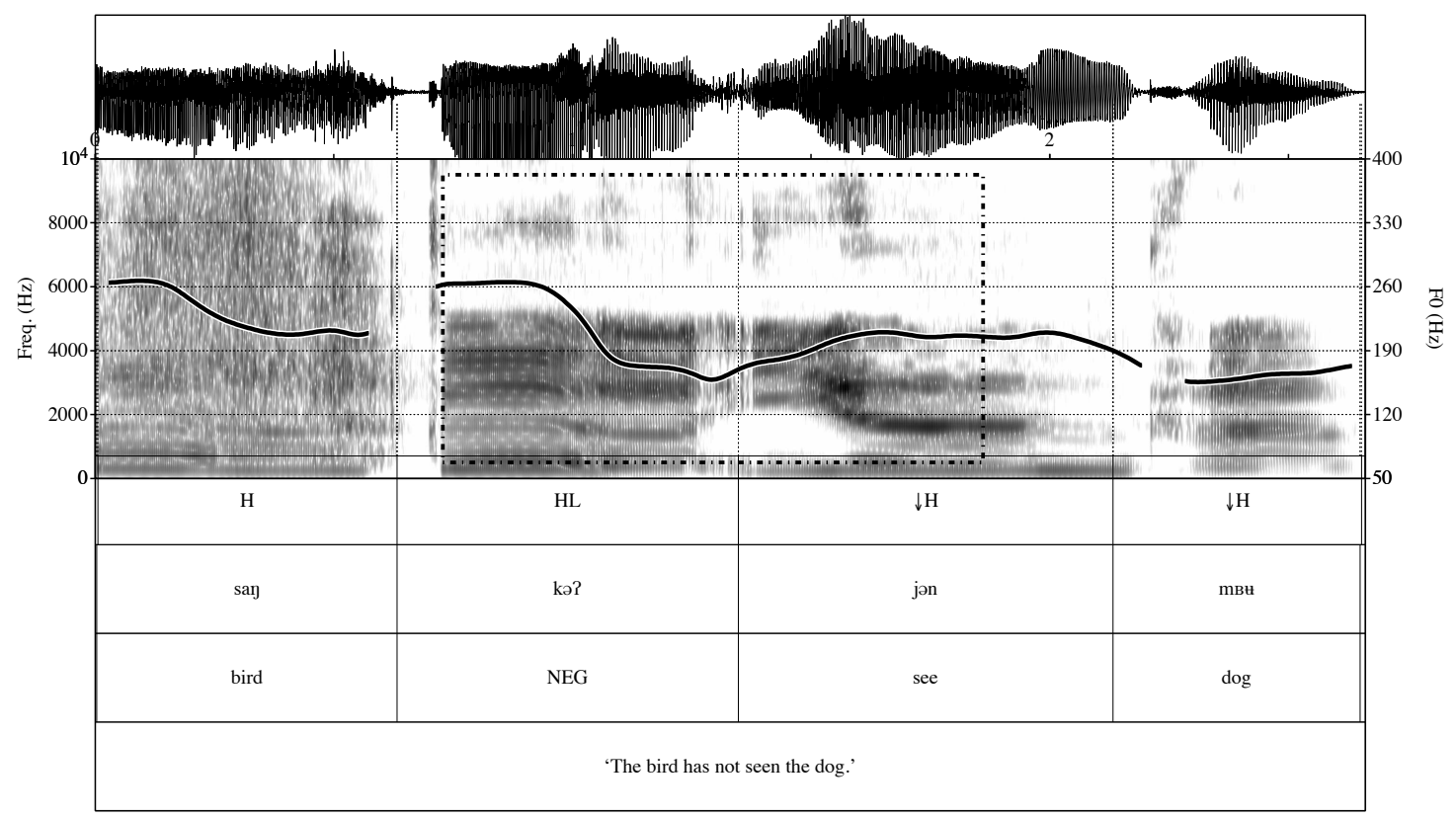

Figure 4: HL Contour Followed by L and Downstepped H

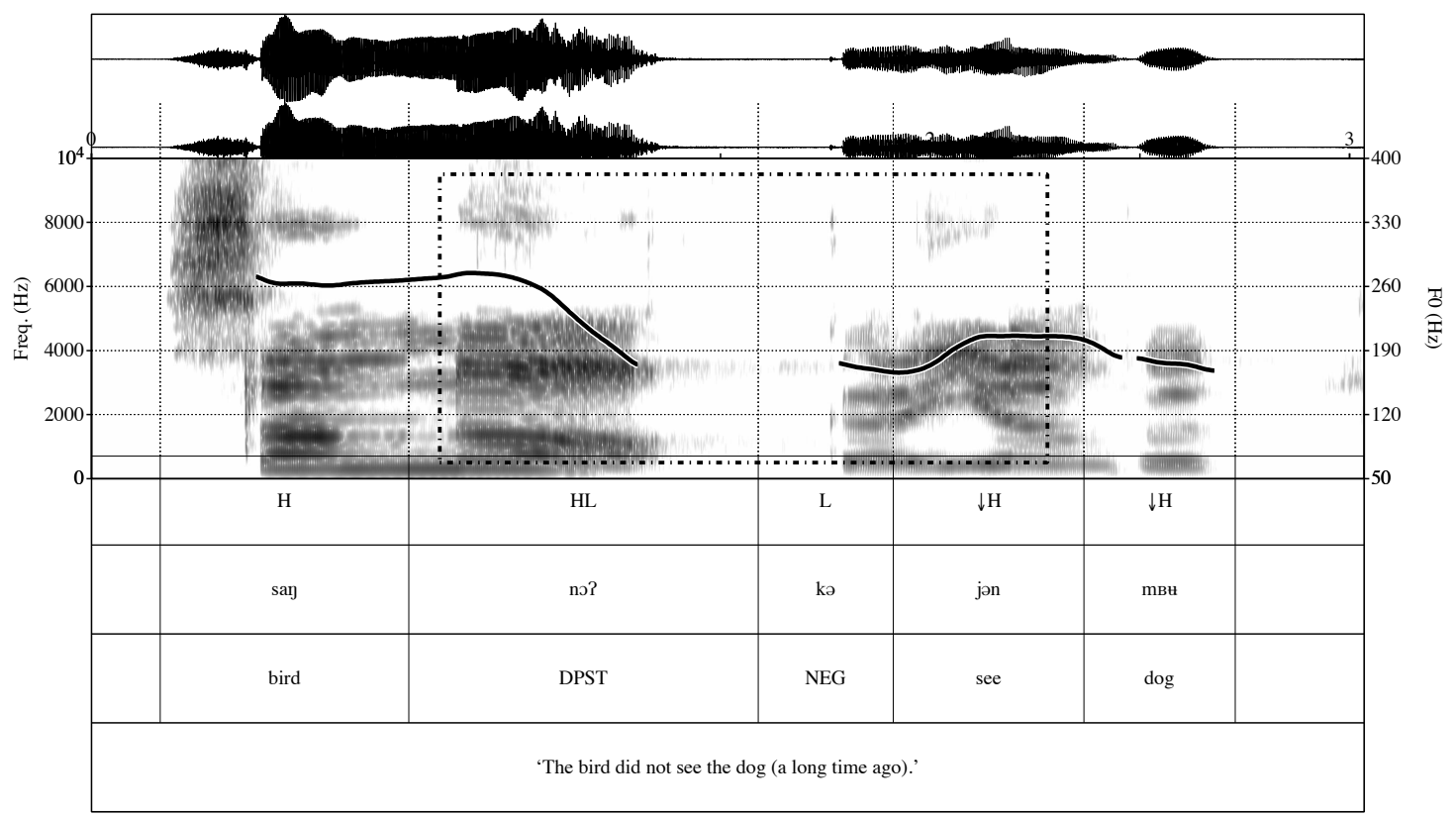


An important generalization about HTA is that it cannot target two consecutive syllables. For example, in a sequence of three words bearing HL contours, only the second of these contours will be targeted for HTA, as in (7b). In this context, application of HTA such that it only targets the first syllable is considered ungrammatical (7b). Likewise, HTA targeting both the first and second syllables is considered highly questionable ${ }^{3}$. Again, [ _] symbolizes a $\mathrm{H}^{\downarrow} \mathrm{H}$ contour, indicating that a syllable has been targeted for HTA. Syllables targeted for HTA are also bolded here.

(7) HTA Targeting Consecutive Syllables is Prohibited

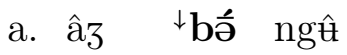
Ange HAB run.away
'Ange always runs away.'

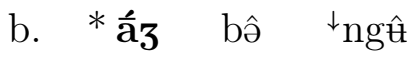
Ange HAB run.away
'Ange always runs away.'
c. ?? áz bó ${ }^{\downarrow} n g \hat{u}$
Ange HAB run.away
'Ange always runs away.'

As seen in (8), multiple non-consecutive syllables can be targeted for HTA within a sentence.

(8) Multiple Non-consecutive Syllables May Be Targeted for HTA

$$
\begin{array}{lllll}
\text { ù } & \text { lú } & \text { t fák } & \text { ndóp kí } \\
\text { 2SG } & \text { DPST } & \text { HOD1 hit } & \text { Q }
\end{array}
$$

'Did you hit (it) that morning?'

Upon closer examination of the distribution of HTA, however, it appears that this process can target the first syllable of a trisyllabic sequence in some cases, rather than the second (9).

(9) HTA Targets the First Syllable in Some Trisyllabic Sequences
a. á3 zí nĝ̂u
Ange HOD1 run.away
'Ange ran away a couple of days ago.'
b. *âz $\downarrow_{\text {zí }} \quad$ nĝे
Ange HOD1 run.away
'Ange ran away a couple of days ago.'
c. áz tyák ngût Ange HOD2 run.away
'Ange ran away this morning.'

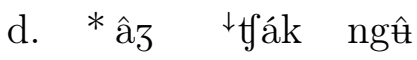
Ange HOD2 run.away
'Ange ran away this morning.'

\footnotetext{
${ }^{3}$ In rapid speech, tone production is highly variable and may result in something phonetically similar to multiple consecutive instances of HTA. However, if asked specifically to rate the tone patterns in (7a-c), speakers highly prefer the form in (a). Likewise, when producing careful speech, speakers unfailingly apply HTA such that it only targets the second syllable in this sequence.
} 
As can be seen from examples (9b,d), failure to apply HTA targeting the first syllable in these utterances is considered flatly ungrammatical.

Why should HTA target the second syllable in some trisyllabic contexts (as in (7)), but the first in others (as in (9))? One of the main differences between the examples in (7) and those in (9) is the tone of the second syllable: while the habitual marker bô in (7) bears a HL contour underlyingly, the hodiernal markers $z i$ and tfák in (9) both bear level $\mathrm{H}$ tones. I will argue in $\S 4$ that this difference in tone is associated with a difference in prosodic status for these two morphemes: specifically, syllables bearing contours are drawn to the head position of a binary foot, while those bearing level tones tend to associate with the non-head position. The domain of HTA, I will argue, is the foot, and those syllables targeted for HTA will always be in head position of the foot. Before moving on to discuss the details of this analysis, I will bring up one more context-sentence initial downdrift-in which differences in phonological behavior between contoured and level syllables seem to signal a difference in prosodic structure.

\subsection{Downdrift}

As mentioned in $\S 2$, Medumba has a process of downdrift whereby the second $\mathrm{H}$ tone in a HLH sequence is produced at a lower pitch level than the first $H$. This process has been argued to occur in parallel grammatical contexts to downstep and effects a similar level of pitch lowering on the second $\mathrm{H}$ tone, leading us to posit that this process is more akin to a regular phonological process than a purely phonetic effect of tonal coarticulation. In (10), we see an example of downdrift in a HLH sequence. Downdrift is represented here with a raised downward arrow $\left[{ }^{\downarrow}\right]$.

(10) Downdrift in a HLH Sequence

$$
\begin{aligned}
& \text { má fà } \quad{ }^{\downarrow} \text { nĝ̂u } \\
& \text { 1SG RPST run.away }
\end{aligned}
$$

'I ran away yesterday.'

In some cases, downdrift appears be blocked from occurring, however. For example, when the first $\mathrm{H}$ and $\mathrm{L}$ of a HLH sequence are realized as level tones on a disyllabic subject, they fail to trigger downdrift on the $\mathrm{H}$ of a following $\mathrm{HL}$ contoured syllable, such as the distant past morpheme ${ }^{4}(11)$.

(11) Downdrift Blocked from Occurring After a H.L Subject

$$
\begin{aligned}
& \text { ndóktà lû nè̀ ná } \\
& \text { doctor DPST go }
\end{aligned}
$$

'The doctor left.'

\footnotetext{
${ }^{4}$ Note that there are additional factors (phonological, morphological and syntactic) which may serve to block downdrift in various environments. The scope of this paper is far too narrow to account for all of these factors, and future work will need to continue to investigate them.
} 
If, however, a subject is used which bears a HL contour rather than a sequence of level $\mathrm{H}$ and $\mathrm{L}$, downdrift does result on the distant past morpheme (12).

(12) Downdrift Possible After a HL Contoured Subject

âz $\quad{ }^{\downarrow}$ lû nغ̀ nó

Ange DPST go

'Ange left.'

Recall that contour tones in African languages are typically treated as sequences of level tones, rather than single units. In principle, then, there should be no reason for a sequence of HL to behave differently phonologically when realized across two syllables than when it is realized on a single syllable. How, then, can this difference be explained? I will argue that the same prosodic difference mentioned previously which causes contoured syllables to be attracted to the head of a foot causes these syllables also to be drawn to the initial position of an intonational phrase. I will argue that it is the positioning of a HL sequence with respect to this prosodic position that allows some sequences, but not others, to trigger downdrift on a following $\mathrm{H}$ tone. In $\S 4$, I discuss the details of such a proposal.

\section{Prosodic Structure and Prominence Asymmetries Be- tween Contoured and Level Syllables}

Before we may move onto the formal analysis of the puzzle presented in $\S 3$ regarding the difference in behavior between contoured and level syllables with respect to HTA and downdrift, it will be necessary to develop a more detailed sketch of the prosodic units we have discussed and illustrate how such units influence the application of these phonological processes. I will first discuss these matters at the level of the foot, and then at the level of the intonational phrase.

\subsection{The Foot}

Though foot structure has been argued to exist in a number of tone languages which do not appear to utilize stress, this structure has not been described in previous work on the Grassfields languages. Evidence for foot structure in tone languages is often less straightforward than that used for languages which are non-tonal, and can vary greatly from language to language. For this reason, before discussing the relationship between HTA and foot structure, I will provide a brief account of evidence from positional vowel contrast neutralization and tone assignment in loanwords to elucidate the structure and construction of feet in Medumba. As will be seen, evidence suggests that Medumba builds trochaic feet which are optimally disyllabic and which are built from right to left.

\subsubsection{Positional Neutralization in Vowel Contrasts}

Positionally-based differences in contrast realization within a word have often been linked to differences in prominence between syllables. Hayes (1995) notes that it is common for vowel 
contrasts to be fully realized in the strong syllable of a foot, but neutralized to some degree in the weak syllable. In a number of Niger-Congo languages, prominence asymmetries between root-initial and noninitial syllables are common, and various authors have suggested that such asymmetries are best captured as a consequence of foot structure (Akinlabi \& Urua 2003; Downing 2004; Harris 2004; Urua 1999). Medumba displays a high degree of positional neutralization in both disyllabic noun and verb roots. In the first vowel of the root, all vowel contrasts can be realized. On the second vowel, however, only schwa can appear $(13)^{5}$.

(13) Positional Vowel Neutralization in Noun and Verb Roots
a. sáyá 'bird' d. léná 'know'
b. vóyó 'dust' e. tfúbá 'speak'
c. zílá 'fat' f. kúbá 'cut'

As can be seen, a full array of vowel contrasts is available on V1 of the words in (14), and only schwa appears in V2 position. This suggests a prominence asymmetry within the word reminiscent of trochaic (strong-weak) foot structure. In the sections that follow, we will see additional evidence in support of this structure.

\subsubsection{Tone Assignment in Loanwords}

Another way that foot structure is seen to be manifested in the phonology of Medumba is in loanwords from English. For the most part, disyllabic loanwords are assigned tone based on the stress pattern of the source word: $\mathrm{H}$ tone is assigned to the stressed syllable, and $\mathrm{L}$ tone is assigned to the unstressed syllable (14).

Default Stress-Based Tone Assignment in Disyllabic English Loans
a. kísìm 'kitchen' [ 'kitfən ]

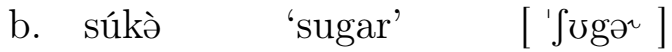
c. ndóktò 'doctor' [ 'dəktə ]

This tone assignment strategy for loanwords is common for many African languages, and may suggest that $\mathrm{H}$ tones associate to prominent positions more easily than $\mathrm{L}$ tones (de Lacy 2002). However, when we move to trisyllabic words with initial stress, the picture becomes a bit more complicated. The stressed syllable in each source word is still assigned a $\mathrm{H}$ tone in the loan; however, the second syllable, which is unstressed in the source language, is also assigned a $\mathrm{H}$ tone. The final syllable, also unstressed in the source, is assigned a $\mathrm{L}$ tone (15).

(15) H Tone Assigned to Penultimate Syllable in English Loans
a. kábíndə̀ 'carpinter' [ 'kapəntə^ ]
b. sásídè 'Saturday' [ 'særəədej ]
c. Émbásì 'embassy' [ 'Embəsi ]

If we assume that feet in Medumba must contain at least one $\mathrm{H}$ tone, the mismatch between stress and $\mathrm{H}$ tone assignment in (15) can be explained by positing that the language

\footnotetext{
${ }^{5}$ Note that an apparent exception for this generalization comes from echo vowels following glottal consonants in some verb roots, which I assume constitute an entirely different phenomenon. Compounds are also excluded from consideration since they display unique prosodic characteristics in a variety of domains.
} 
builds disyllabic trochees from right to left. Rather than form an suboptimal foot with two $\mathrm{L}$ toned syllables, the language assigns an additional $\mathrm{H}$ tone to the penultimate syllable of each trisyllabic word. The proposed foot structure for each of these words is represented in (16).

(16) Right-to-left Footing of Trisyllabic English Loanwords
a. ká ( bí.ndò )FT
b. sá ( sí.dè $)_{\mathrm{FT}}$
c. ́́m ( bá.sì )FT

As can be seen in (16), assignment of a $\mathrm{H}$ tone to the penultimate syllable of trisyllabic English loans evinces a trochaic foot pattern where the penultimate syllable is the head of the trochee.

To summarize, I have provided evidence from positional vowel neutralization and tone assignment in loanwords that Medumba builds optimally disyllabic trochees from right to left. I now move on to show how the distribution of HTA is influenced by foot structure and, specifically, by a prominence asymmetry between contoured and level syllables at the level of the foot.

\subsubsection{High Tone Anticipation}

We discussed in $\S 3$ the fact that HTA cannot target two syllables which are linearly adjacent. Since we know that Medumba builds optimally disyllabic feet, this pattern can be accounted for if we simply assume that the domain of HTA is the foot. Recall that tone assignment in loanwords provides us with evidence that feet are built from right to left. From this, we would predict that, in a series of three syllables where both the first and second syllables could potentially be targets for HTA, the second syllable will be targeted. As we have seen, this is precisely the pattern we find when the three syllables in the sequence all bear contour tones (17).

(17) HTA Targets $\sigma_{2}$ in a Sequence of 3 Contours

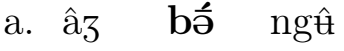
Ange HAB run.away
'Ange always runs away.'

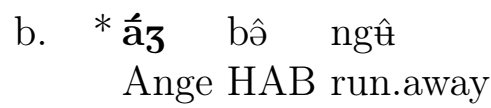
'Ange always runs away.'

The above pattern gives further evidence for the right-to-left construction of feet as in (18).

(18) Foot Structure for Three Consecutive HL Contoured Syllables

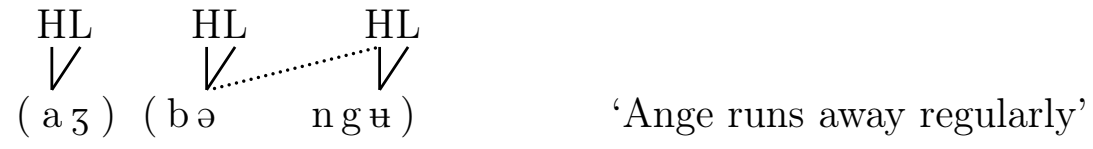

However, recall that if we look instead at a sequence of three syllables where the second syllable bears a level H tone instead of a HL contour, we find that HTA is forced to target the first syllable in the sequence (19). 
HTA Targets $\sigma_{1}$ in a Contour-Level-Contour Sequence

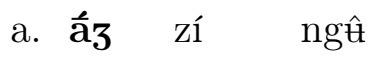
Ange HOD1 run-away

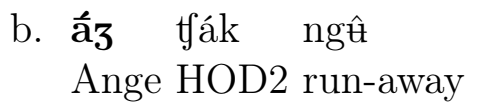
'Ange ran away a few days ago.'
'Ange ran away this morning.'

This pattern of HTA seems to occur for any sequence of three syllables with a HL.H.HL pattern, regardless of the syllable shapes in question or any other segmental features they may carry. It thus seems as if this shift in the target of HTA between the examples in (17) and those in (19) is related to the tone pattern found on the second syllable.

But what is it, exactly, that makes these syllables behave differently from one another? Recall our original proposal that HTA is constrained to occurring within a trochaic foot, and that this process always targets the head of a foot. It is quite common crosslinguistically for tone spreading of the regressive variety to target positions which are prosodically prominent (Hyman \& Schuh 1974). Perhaps, then, the difference between contoured and level syllables stems from the fact that contours are preferred in head (prominent) position of a foot, while level toned syllables are preferred in the nonhead position. Applying our original analysis to the data at hand, the foot structure proposed for the examples in (19) would be as in (20).

Proposed Foot Structure for Contour-Level-Contour Sequences

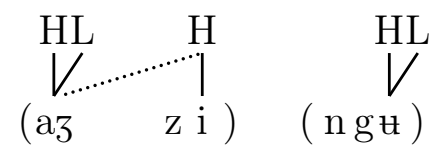

'Ange runs away regularly'

As can be seen in (20), the default right-to-left footing pattern has been altered in order to ensure that prominent positions are occupied by syllables bearing contours, rather than those bearing level tones. In the following section, we will see that the phenomenon of contoured syllables being attracted to prominent positions is not limited solely to feet, but is also evidenced at the level of the intonational phrase.

\subsection{The Intonational Phrase}

I will now return to the phenomenon of sentence initial downdrift and attempt to explain variation in the application of this process using a similar prominence-based account as was provided for HTA. First, I provide a brief overview of the structure of the intonational phrase. This prosodic unit has been analyzed in many languages as roughly coinciding with the clause or sentence, or what Downing (1970) referred to as the 'root clause'. In Medumba, this is precisely domain over which a sequence of downsteps or downdrifts begins and ends. Downdrift and downstep begin to occur after the first $\mathrm{H}$ tone in the first conjoined clause in (21), but the pitch ceiling is reset at the first syllable of the second clause to around the same pitch level as the initial $\mathrm{H}$ tone of the sentence. 
(21)

Downstep/Downdrift Reset at IP Boundary

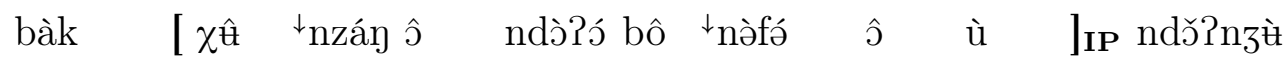

3PL.EX have bird FOC only two INF.give FOC 2SG but

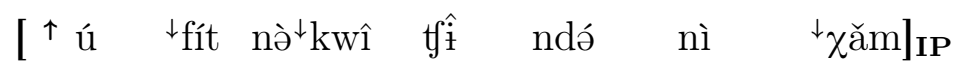
2SG may INF.take DEM potatos PROX ten

'We have only two birds for you, but you may have those ten potatoes.'

In Figure 5, the first syllable of each of the two conjoined intonational phrases is circled with a dotted line. In comparing these two circled portions with the rest of the pitch track, the pitch reset at the start of the second IP is quite clear.

Figure 5: Downstep and Upstep in the Intonational Phrase

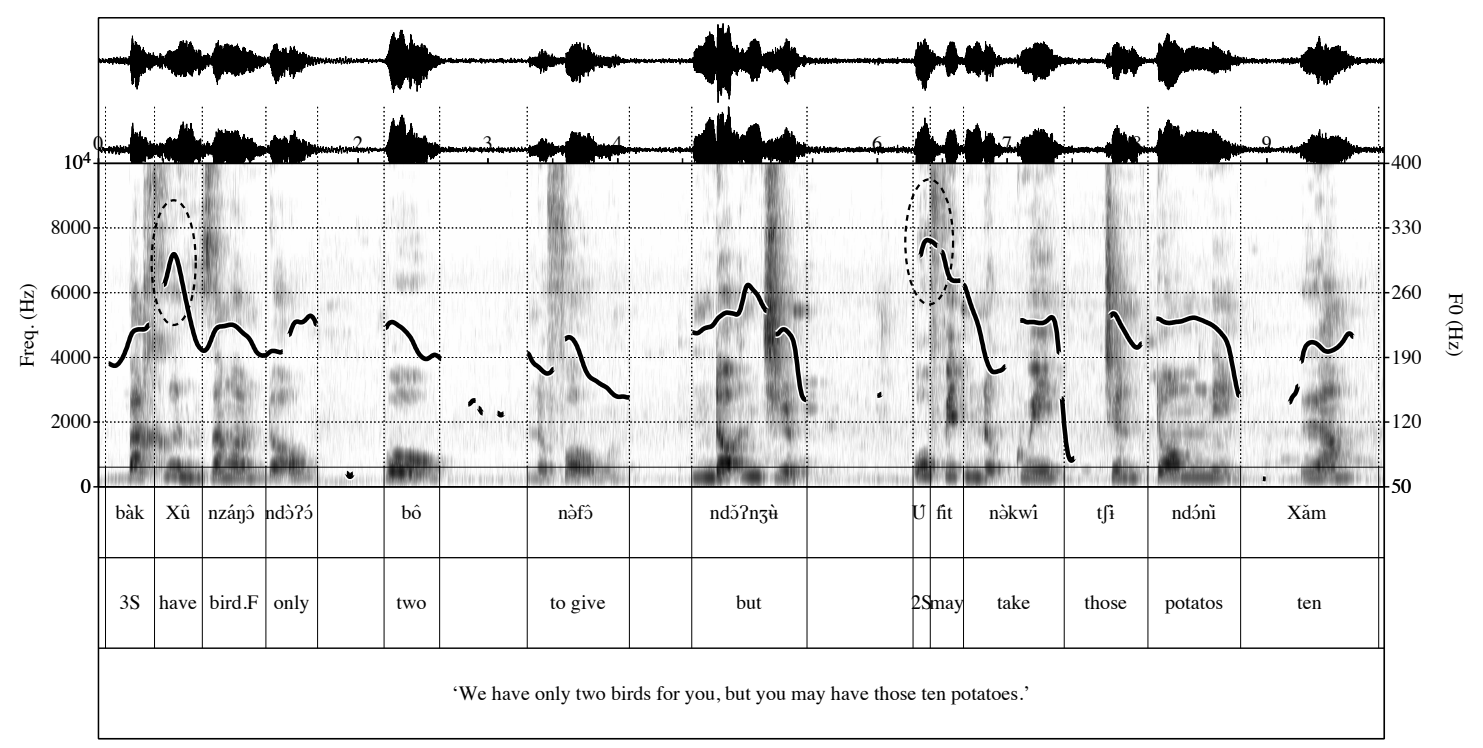

Moving forward based on our assumption that the intonational phrase is the domain over which sequences downstep and downdrift begin and end, one approach to explaining the variation we see with respect to HL contoured syllables vs. H.L level syllable sequences is to assume that the former, but not the latter, is included within the IP when it occurs in subject position. Thus, for the sentences we saw previously in (11) and (12) (repeated here in $(22 \mathrm{a}, \mathrm{b}))$, the IP structures would be as written to the left of each sentence.

(22) Intonational Phrase Structures for H.L Level and HL Contoured Subjects

a. ndóktò lû $\quad$ nè๋ nó $\rightarrow$ ndóktò IP[ lû nè $\grave{~}^{\downarrow}$ nó ]IP doctor DPST go

'The doctor left.' 
b. âz ${ }^{\downarrow}$ lû nè̀ná $\rightarrow \quad$ IP [ âz ${ }^{\downarrow}$ lû nè̀ nó $]_{\text {IP }}$
Ange DPST go

'Ange left.'

Patterns in the placement of left edge boundary tones also provide evidence for the different prosodic status of sentence-initial words ${ }^{6}$. Notice that, in the following sentences, a $\mathrm{H}$ boundary tone attaches to underlying toneless pronouns before a level-toned $\mathrm{H}$ syllable, but not before a HL contoured syllable (23).

Variation in H Boundary Tone Attachment Before HL Contoured vs. Level Syllables

a. bák ${ }^{\downarrow}$ zú ${ }^{\downarrow}$ kòlò

2PL.EX eat banana

'We have eaten the banana.'

c. má fà ${ }^{\downarrow}$ njən mvàn

1SG RPST see chief

'I saw the chief yesterday.' b. bàk lû $\quad{ }^{\downarrow}$ nčn ${ }^{\downarrow}$ ndónó

2PL.EX DPST go market

'We went to the market a long time ago.'

d. mà fá nján $\hat{\jmath}$ mvòn

1SG RPST see FOC chief

'I saw the chief yesterday (not the teacher).'

If we assume that the boundary $\mathrm{H}$ tone is associated with the left edge of an intonational phrase, its avoidance of the pronoun before a HL contoured syllable can be accounted for by assuming that the contoured syllable, rather than the pronoun, is the first element of the intonational phrase. In these cases, the boundary $\mathrm{H}$ associates to the contour and is absorbed by the $\mathrm{H}$ tone already present on the contour. Without a boundary tone to associate to it, the toneless pronoun is assigned a L tone by default. In (24), I provide the proposed IP structure for (23a), and in (25) I provide the structure for (23b). The $\mathrm{H}$ tone represented in autosegmental notation is meant to signify the IP boundary $\mathrm{H}$ tone.

Proposed Intonational Phrase Structure for (23a): [ bák ` `zú kòlò ]IP

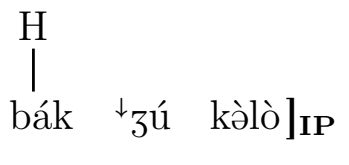

Proposed Intonational Phrase Structure for (23b): bàk

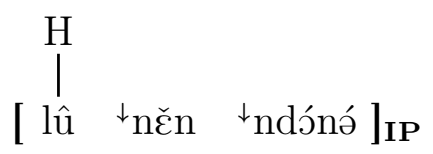

Indeed, one of the rare cases in which a subject pronoun may bear a $\mathrm{H}$ tone before a HL contour is in subject focus constructions, where evidence suggests the focused subject occupies its own intonational phrase (Franich 2013) (26).

\section{(26) Separate Intonational Phrases in Subject Focus Constructions}

\footnotetext{
${ }^{6}$ What is referred to here as a 'boundary tone' has been historically associated in various constructions across the Mbam-Nkam languages with different tense and aspect markers, argued by some to remain morphologically productive in some of these languages (Hyman \& Tadadjeu 1976). Given the presence of floating $\mathrm{H}$ tones at or near the left edge in such a wide variety of tense, aspect and mood configurations in Medumba and the lack of systematic correspondences between $\mathrm{H}$ tone and any specific morphological function in these constructions, we treat these tones as representative of a single boundary-related phenomenon.
} 


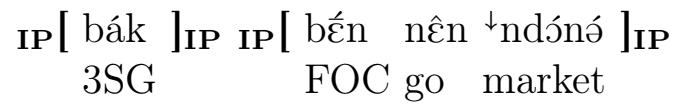

'We are the ones who went to the market.'

Finally, Franich (2013) demonstrates that additional phonetic evidence serves to differentiate the IP-initial position from the proposed 'pre-IP' position. Nouns occurring in IP-initial position are shown to exhibit upstep while the same nouns in pre-IP position do not, and IP-initial nouns are produced with slightly longer duration than pre-IP nouns. All of this evidence taken together seems to confirm patterns similar to those discussed for the foot: 1) the initial position of the intonational phrase is a prominent position; and 2) contoured syllables are attracted to this position of prominence.

\section{Tonal Prominence or Syllable Weight?}

To sum up so far, I have provided an overview of variation in two tonal processes, High Tone Anticipation and sentence initial downdrift, and argued that this variation centers around a difference in the prosodic status of contoured syllables versus level syllables. Specifically, I have argued that contoured syllables are attracted to prominent positions both at the level of the foot and at the level of the intonational phrase. We have not yet identified, however, what the key difference between these two types of syllables is. One possibility is that contoured syllables are more prominent than level toned syllables purely because of their tonal properties. For example, de Lacy (2002) provides evidence from a variety of languages suggesting that $\mathrm{H}$ tones tend to associate to prominent positions, while $\mathrm{L}$ tones associate to non-prominent positions. $\mathrm{H}$ and $\mathrm{L}$ tones are thus said to be arranged hierarchically on a prominence scale, as in (27).

$$
\mathrm{H}>\mathrm{L}
$$

Recall that we have seen evidence from Medumba loanwords that $\mathrm{H}$ tones are more prominent than L tones, since they are systematically assigned even to syllables which are unstressed in the source language if they would fall in the head position of a foot in Medumba. When present, however, contour tones are preferred in the head position of a foot, suggesting that the tonal hierarchy for Medumba might look as in (28).

$$
\mathrm{HL}, \mathrm{LH}>\mathrm{H}>\mathrm{L}
$$

Another possibility, and one that has been investigated recently by Qu \& Goad (In progress) for Mandarin Chinese, is that a bipartite relationship holds between tone height (H vs. L) and tone dynamism (contoured vs. level) with prominence such that each property may be associated with its own separate prominence scale.

However, an interesting set of facts from downdrift behavior in loanwords suggests that tone may not be the only factor driving the prominence asymmetry we see between contoured and level syllables. We have seen that a disyllabic sequence containing a level $\mathrm{H}$ followed by a level $\mathrm{L}$ cannot trigger downdrift on a following $\mathrm{H}$ when this disyllabic word is in subject position. However, a few trisyllabic loanwords from English of the tone melody L.H.L, 
including 'tomato' and 'potato', show variation in their ability to trigger downdrift on a following $\mathrm{H}$ syllable when they occur in subject position ${ }^{7}$ (29).

(29) Loanwords from English Displaying Variation in Downdrift Behavior

a. Variant 1: Without downdrift

tùmátù lû $\quad{ }^{\downarrow}$ něn ${ }^{\downarrow}$ ndóná

tomato DPST go market

'The tomato went to the market.'

b. Variant 2: With downdrift

tùmátù ${ }^{\natural}$ û $\downarrow^{\downarrow}$ Ěn ${ }^{\downarrow}$ ndóná

tomato DPST go market

'The tomato went to the market.'

Upon closer inspection, variation with respect to downdrift after these words does not appear to be completely random: the length of the vowel of the second syllable for the word tùmátù is consistently produced as longer in the second variant than it is in in the first variant. In fact, as shown in Table 1 below, the first and third vowels of the word tùmátù are produced with roughly the same duration across the two variants, while the second vowel in Variant 2 is produced up to twice as long as the second vowel in Variant 1.

Table 1: Differences in Vowel Length for Variants of tùmátù

\begin{tabular}{|c|l|l|l|l|c|}
\hline Variant & Measure & \multicolumn{1}{|c|}{ V1 $(\mathbf{m s})$} & \multicolumn{1}{|c|}{ V2 $(\mathbf{m s})$} & \multicolumn{1}{|c|}{ V3 (ms) } & Triggers Downdrift? \\
\hline \multirow{3}{*}{ 1. [tù.má.tù] } & & & & & \\
& Avg. & 50.75 & 140.00 & 120.12 & No \\
& Range & $50.30-60.00$ & $130.40-140.50$ & $100.50-130.80$ & \\
& SD & 3.30 & 5.00 & 13.50 & \\
\hline \multirow{2}{*}{ 2. [tù.má..tù] } & Avg. & 50.70 & 210.40 & 140.70 & Yes \\
& Range & $40.00-70.00$ & $200.00-230.00$ & $140.00-150.40$ & \\
& SD & 15.30 & 12.50 & 10.00 & \\
\hline
\end{tabular}

What the data in Table 1 show is that vowel duration may be a sufficient cue for inducing downdrift in some environments. This observation calls into question the purely tonal nature of the prominence asymmetries we have discussed. As has been shown previously, contoured syllables are regularly produced with longer duration than their level-toned counterpartsperhaps this durational difference signals a vowel length distinction which enables contoured (long) vowels to trigger downdrift where level-toned (short) vowels cannot. This possibility will be explored in more depth in $\S 6$.

\footnotetext{
${ }^{7}$ Clearly, these sentences are quite unnatural given the agentive properties assigned to a tomato. Since tone can interact in complex ways with argument structure, however, it was necessary to use rather odd constructions to test for downdrift. The context given to the participant was one in which a person dressed as a tomato (say, for Halloween) goes to the market, or where a tomato comes alive as in a children's television show and can take on human qualities.
} 


\section{Contour Tones and Syllable Weight}

The relationship between vowel duration and downdrift described for the loanwords in $\S 6$ brings up questions about the true nature of the prominence asymmetries we have observed between contoured and level syllables in Medumba. It also brings up some interesting questions with regard to the more general crosslinguistic relationship between vowel length and contour tone distribution.

\subsection{A Subphonemic Weight Distinction}

It has been observed for many contour tone languages that contours tend to be restricted to long vowels (Gordon 2001; Zhang 2002, 2004). This preference has been argued to have a phonetic motivation since vowels have more energy than other segment types at higher frequencies, hence allowing for better recoverability of $f_{0}$. Given that the tonal information in contoured syllables is more complex than in level syllables, it makes sense that contours should be preferred on syllables with higher energy profiles. Indeed, a distinction in weight based solely on vowel length is quite common, especially where tonal phenomena are concerned.

However, this connection between vowel length and contour tones has mostly been described in existing literature for languages which have clear phonemic vowel length distinctions. As previously mentioned, Medumba has few minimal pairs for vowel length, and these are largely found in loanwords. On the whole, evidence of a phonemic length contrast outside of the contour-level distinction is scarce. However, it is not out of the question that a full phonemic contrast could eventually emerge in the language. In some cases, such as that of Korean and the Weert dialect of Dutch, contour tones have been argued to give way to long vowels (Kown 2003; Heijmans 2003). (Yu 2010) shows that listeners perceive contoured syllables as having longer duration than level-toned syllables, even when these syllables are acoustically equivalent in duration. The author proposes that changes such as those which appear to have occurred in Korean and the Weert dialect may have been brought about due to hypocorrection (Ohala 1993), such that listeners, after repeatedly hearing certain types of contoured syllables as longer, eventually begin to interpret the additional duration as intentional on the part of the speaker. An intermediate stage of the change may thus involve listeners treating (some) contoured syllables as underlyingly long, and level toned syllables as underlyingly short. This bears striking resemblance to the situation we find in Medumba.

\subsection{Representing Syllable Weight}

Since there appears to be ample evidence that the weight distinction proposed for Medumba is largely phonetically-driven, I appeal to a model of syllable weight which is also grounded in phonetic considerations. Gordon (2002a) shows a connection between phonological weight and the relative perceptual energy between syllables, which is stated as a measurement of loudness over time. Syllables which behave as heavy in a given language also tend to display greater perceptual energy. As we have seen, vowel length for contoured syllables is significantly longer than that for level-toned syllables for all syllable shapes. Since the total 
perceptual energy of a segment is calculated as a function of segment duration, perceptual energy will naturally be higher for contoured syllables than for level toned syllables in Medumba. Gordon formalizes this model using a set of structurally simple phonological representations built from skeletal slots. In the case of a weight opposition between syllables with long vowels and all other syllables, the representations of syllables bearing long vowels vs. those bearing short vowels are shown in (30). The feature SYLLABIC is used to indicate acoustic properties of nuclear segments such as increased intensity.

Vowel Length Weight Distinctions Under Gordon's Skeletal Slot Model
a. Representation for $(\mathrm{C}) \operatorname{VV}(\mathrm{C})$
b. Representation for $(\mathrm{C}) \mathrm{V}(\mathrm{C})$
$\left[(\mathrm{X})[\mathrm{XX}]_{\mathrm{RIME}}(\mathrm{X})\right]_{\sigma}$
Syll
$\left[(\mathrm{X})[\mathrm{X}]_{\mathrm{RIME}}(\mathrm{X})\right]_{\sigma}$
Syll

In the following section, I will build on these representations in developing a constraint set to analyze the observed prominence asymmetries between heavy (contoured) and light (level) syllables in Medumba. Since vowel length has been posited to play a central role in determining syllable weight, contoured syllables will henceforth be marked with long vowels $(\mathrm{V}:$ ), and level syllables with short vowels (V).

\section{Analysis of Prominence Asymmetries in Medumba}

Having established the criteria on which weight distinctions are based in Medumba, I begin by outlining a set of constraints which will capture prominence asymmetries between heavy and light syllables at the level of the foot. Recall that, all else being equal, Medumba opts to build disyllabic trochees. To model this, I will first incorporate the constraint TrocheE from Prince \& Smolensky (1993) which dictates that all feet must be left-headed (31). I propose that this constraint is undominated in Medumba and will thus exclude it from the tableaux that follow.

(31) TrocheE: All feet are left-headed

To model the proposed disyllabic foot structure, I will utilize the constraint FTBIn(SYLL) from Prince \& Smolensky (1993) (32).

(32) FtBin(Syll): Feet are disyllabic

Finally, we must formulate a constraint that can enforce the attraction of heavy/contoured syllables to the head position-the leftmost position-of a foot. To do this, I will adapt an alignment constraint which makes reference to syllables bearing long vowels based on the representation presented in $\S 6(33)$.

$\operatorname{Align}\left([(\mathrm{X}) \underset{\substack{\mathrm{XX} \\ \text { Syll }}}{[\mathrm{RImE}}(\mathrm{X})]_{\sigma}, \mathrm{L}, \mathrm{Ft}, \mathrm{L}\right)$ : Syllables bearing long vowels must align with the left edge of a foot 
The tableau in (34) shows the crucial ranking of the constraints FTBIN and ALIGN ([XX],L) which ensures that disyllabic feet will be built even at the expense of having a heavy syllable in non-head position.

Disyllabic feet: FTBIn $\gg \operatorname{Align}([\mathrm{XX}], \mathrm{L})$

\begin{tabular}{|c|c|c|}
\hline / â:3 bô: ndábò / & FTBIN(SYLL) & $\operatorname{Align}([\mathrm{XX}], \mathrm{L})$ \\
\hline a. 贾 (á́:3 bâ: ) (ndábə̀ & & * \\
\hline ( â:3 ) ( bấ: ndá ) (bò ) & $*$ !* & \\
\hline ( â:3 ) ( bô: ) ( ndábò ) & $* !^{*}$ & \\
\hline
\end{tabular}

Another property of feet in Medumba that we have discussed is that, all else being equal, they are build from right to left. To model this, I invoke the constraint Align(PRWD,R,FT,R) from McCarthy \& Prince (1993a) which dictates that a prosodic word align at the right edge with a foot $^{8}(35)$.

(35) Align(PRWD,R,FTR): The right edge of each prosodic word must match the right edge of some foot.

As we have seen, when a mix of heavy/contoured and light/level syllables occurs, footing may be altered in order to ensure that heavy syllables occur in the head position of feet. The crucial ranking of $\operatorname{Align}([X X], L) \gg \operatorname{Align}(P R W D, R)$ which produces this pattern is demonstrated in (36).

(36) Heavy syllables in head position of a foot: $\operatorname{Align}([X X], L) \gg \operatorname{Align}(\operatorname{PRWD}, \mathrm{R})$

\begin{tabular}{|c|c|c|c|c|}
\hline & / â:3 zí nĝ̂u: / & FTBIN(SYLL) & $\operatorname{ALIGN}([\mathrm{XX}], \mathrm{L})$ & Align(PRWD,R) \\
\hline a. & 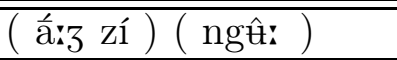 & $\bar{*}$ & & * \\
\hline b. & 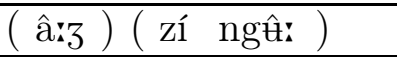 & * & $* !$ & \\
\hline c. & $($ â:3 ) ( zí ) ( nĝ̂t: ) & **!* & & $*$ \\
\hline
\end{tabular}

In (37), we see that this ranking also ensures that a sequence of three equal heavy (or light) syllables will obey default right-to-left footing.

$$
\text { Right-to-left foot building: FtBin } \gg \operatorname{Align}([X X], L) » \operatorname{Align}(\operatorname{PrWD}, R)
$$

\begin{tabular}{|c|c|c|c|}
\hline / â:3 bô: nĝ̂t: / & FTBIN(SYLL) & $\operatorname{ALIGN}([\mathrm{XX}], \mathrm{L})$ & $\operatorname{AligN}(\mathrm{PRWD}, \mathrm{R})$ \\
\hline 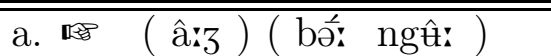 & $\bar{*}$ & F & \\
\hline ( á:3 bô: ) ( ngĥt: ) & * & $*$ & $* 1$ \\
\hline$\left(\hat{a}_{13} 3\right)(\mathrm{b} \hat{\mathbf{i}} \mathbf{z})(\mathrm{ng} \hat{\mathrm{t}} \mathbf{i})$ & **!* & & $*$ \\
\hline
\end{tabular}

We now move on to model prominence asymmetries at the level of the intonational phrase. To do so, several more constraints will be utilized. First, in order to capture the prominence

\footnotetext{
${ }^{8}$ Important to mention is the fact that words in Medumba are largely monosyllabic, meaning that feet and prosodic words will quite often be constructed across morphological word boundaries. The non-isometry of prosodic and morphological words has been discussed for a variety of Bantoid languages, including Dschang, a closely related Grassfields language (Hyman 1985).
} 
effect, I utilize the constraint Align(Stress, L, IP) which holds that a stressed syllable is always aligned with the left edge of an intonational phrase (38). This constraint is unviolated in the language, and I thus exclude it from the tableaux in this section.

(38) Align(Stress, L, IP): A stressed $\sigma$ is aligned with the left edge of an Intonational Phrase (IP)

In addition to this constraint, I utilize Prince's (1990) Stress-to-Weight Principle, which holds that stressed syllables should be heavy (39).

Stress-To-Weight: Stressed $\sigma$ 's are heavy

I also invoke the constraint IDENT-IO[Vowel-Lenth] (Gordon 2006) which militates against vowel lengthening (40).

(40) Ident-IO[Vowel-Length]: Vowel length in the input must correspond to vowel length in the output

To illustrate the ranking between IDENT-IO[V-LENGTH] and STW, we can look at an example which contains no contoured syllables. In (41), we see that IDENT-IO[V-LENGTH] outranks STW, yielding an output in which the initial syllable of the intonational phrase remains short. Stressed syllables are underlined.

(41) Faithfulness to vowel length preferred over lengthening to observe STW: IDENTIO[V-LEngth] $\gg$ STW

\begin{tabular}{|c|c|c|c|c|c|}
\hline \multicolumn{4}{|c|}{ / má fà njónó / } & ID [V-LEN] & STW \\
\hline 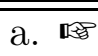 & $\overline{\mathrm{IP}}$ & "( má fò $)_{\mathrm{PP}} \downarrow(\text { njónó })_{\mathrm{PP}}$ & $\overline{\mathrm{IP}}$ & & * \\
\hline b. & $\overline{\mathrm{IP}}$ & $(\underline{\text { mó: }} \text { fò })_{\mathrm{PP}}{ }^{\downarrow}(\text { njónó })_{\mathrm{PP}}$ & IP & $* !$ & \\
\hline
\end{tabular}

Turning now to examples in which heavy/contoured syllables are available to satisfy STW, we must allow for material at the beginning of the sentence to be skipped to ensure that a heavy syllable resides in IP-initial position. To model this effect, IDENT-IO[VLEngth] will crucially outrank an additional PARSE-PhrASE constraint, which requires that all prosodic phrases are parsed into an intonational phrase (42) ${ }^{9}$.

(42) PARse-Phrase: Every Phonological Phrase (PP) belongs to an Intonational Phrase

Due to the ranking of IdEnT-IO[V-Length] over PARSE-Phrase, where heavy syllables are available, violations of PARSE-PHRASE will be tolerated in order to both allow for a heavy syllable to occur in IP-initial position and to avoid lengthening of short syllables to satisfy STW (43).

\footnotetext{
${ }^{9}$ Note that systematic differences have yet to be identified between the Prosodic Word and Prosodic Phrase levels, so these units are used interchangeably for our purposes here. In respecting the Strict Layer Hypothesis (Selkirk 1984) in assuming that each layer of the prosodic hierarchy strictly dominates the next layer down, I formulate the PARSE constraint in terms of prosodic phrases rather than prosodic words.
} 
(43) Heavy syllables in IP-initial position; extraprosodicity preferred over vowel lengthening: ID $[\mathrm{V}-\mathrm{LEngth}] \gg \mathrm{STW} \gg$ PARSE-Phrase

\begin{tabular}{|c|c|c|c|c|c|}
\hline & / ndóktò lû: jón sáyó / & & ID $[\mathrm{V}-\mathrm{LEN}]$ & STW & PRS-P \\
\hline a. 罯 & 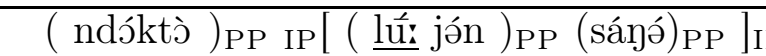 & & & & * \\
\hline $\mathrm{b}$. & $\mathrm{IP}\left[(\underline{\text { ndóktò }})_{\mathrm{PP}}^{\downarrow}(\text { lú̃: jón })_{\mathrm{PP}}(\text { sáyá })_{\mathrm{PP}}\right.$ & IP & & $* !$ & \\
\hline c. & ${ }_{\mathrm{IP}}\left[\left(\underline{\text { ndósktò }}_{\mathrm{PP}}{ }^{\downarrow}(\text { lú: jón })_{\mathrm{PP}}(\text { sáyó })_{\mathrm{PP}}\right]\right.$ & IIP & $* !$ & & \\
\hline
\end{tabular}

A ranking summary for prominence asymmetries in Medumba is given in (44).

(44) Ranking summary for prominence asymmetries

a. Heavy/contoured syllables in head position of a disyllabic foot:

FtBin(Syll) $\gg \operatorname{Align}([X X], L) \gg \operatorname{Align}(\operatorname{PrWD}, R)$

b. Heavy/contoured syllabes in initial (stressed) position of an intonational phrase: ID [Vowel-Length] $\gg$ Stress-To-Weight »PARse-Phrase

\section{Conclusion}

To conclude, I have presented evidence for prominence asymmetries in Medumba between syllables bearing contour tones and those bearing level tones. I have argued, based on variation in the application of two tonal processes-High Tone Anticipation and downdriftthat syllables bearing contours are preferred both in the head position of a foot and in the initial (stressed) position of an intonational phrase. I have furthermore argued that these asymmetries, rather than being driven by purely tonal properties, are based in durational differences between contoured and level syllables which contribute to a subphonemic weight distinction in the language. This distinction has been modeled using Gordon's (2002a) representations for phonetically-motivated syllable weight.

A number of questions still remain with respect to the nature of contour tones in Medumba, the most pressing of which having to do with the relative prominence or weight of HL contours and LH contours. Though I have framed the discussion in this paper in terms of a contour vs. level dichotomy, many of the processes discussed here deal only with HL contours and thus cannot be directly used to diagnose the status of a LH contour. Further investigation into potential phonetic and phonological differences between these two types of contours will be necessary. I have also limited the discussion in this paper to lexical contours, though an understanding of how these processes are influenced by morphological contours will of course be useful for developing a more comprehensive theory of tone-vowel length-weight interactions in Medumba.

For now, I have highlighted a number of previously unreported prosodic phenomena in Medumba which have proven useful in disentangling some of the very complicated tonal patterns in this language. Furthermore, I have proposed that Medumba exhibits signs of prominence asymmetries which could potentially be analyzed in terms of stress. This work aims to contribute to the growing body of literature aimed at understanding the complex crosslinguistic interactions between tone, prominence, and syllable weight. 


\section{$9 \quad$ References}

Akinlabi, Akinbiyi \& Eno-Abasi Urua. 2003. Foot structure in the Ibibio verb. Journal of African Languages and Linguistics 24(2). 119-160.

Downing, Bruce. 1970. Syntactic structure and phonological phrasing in english: University of Texas at Austin dissertation.

Downing, Laura. 2004. What African languages tell us about accent typology. ZAS Papers in Linguistics 37. 101-136.

Franich, Kathryn. 2013. High tone anticipation and prosodic structure in Medumba.

Genzel, Susanne \& Frank Kügler. 2011. Phonetic realization of automatic (downdrift) and non-automatic downstep in Akan. In Proceedings of the international congress on phonetic sciences xvii, 735-738. Hong Kong.

Gordon, Matthew. 2001. A typology of contour tone restrictions. Studies in Language 25. 405-444.

Gordon, Matthew. 2002a. A phonetically-driven account of syllable weight. Language 78. $51-80$.

Gordon, Matthew. 2006. Syllable weight: Phonetics, phonology, and typology. London: Routledge.

Harris, John. 2004. Release the captive coda: The foot as the domain of interpretation. In Phonetic interpretation: Papers in laboratory phonology, vol. 6, 103-129. Cambridge, MA: Cambridge University Press.

Hayes, Bruce. 1995. Metrical stress theory: Principles and case studies. Chicago: University of Chicago Press.

Heijmans, Linda. 2003. The relationship between tone and vowel length in two neighboring Dutch Limburgian dialects. In Paula Fikkert \& Haike Jacobs (eds.), Development in prosodic systems, 7-45. Mouton de Gruyter.

Hyman, Larry M. 1985. Word domains and downstep in Bamileke-Dschang. Phonology 2. $47-83$.

Hyman, Larry M. \& Russel G. Schuh. 1974. Universals of tone rules: Evidence from West Africa. Linguistic Inquiry 5. 81-115.

Hyman, Larry M. \& Maurice Tadadjeu. 1976. Floating tones in Mbam-Nkam. Southern California Occasional Papers in Linguistics 3. 57-111.

Kown, Kyung-Keun. 2003. Prosodic change from tone to vowel length in Korean. In Paula Fikkert \& Haike Jacobs (eds.), Development in prosodic systems, 67-89. Mouton de Gruyter. 
de Lacy, Paul. 2002. The interaction of tone and stress in optimality theory. Phonology 19. $1-32$.

McCarthy, John \& Alan Prince. 1993a. Generalized alignment. Yearbook of Morphology $79-153$.

Ohala, John. 1993. The phonetics of sound change. In Charles Jones (ed.), Historical linguistics: Problems and perspectives, 237-278. London: Longman.

Pike, Kenneth. 1948. Tone languages: A technique for determining the number and type of pitch contrasts in a language, with studies in tonemic substitution and fusion (University of Michigan Publications in Linguistics 4 xii). Ann Arbor: University of Michigan Press.

Prince, Alan. 1990. Quantitative consequences of rhythmic organization. In Karen Deaton, Manuela Noske \& Michael Ziolkowski (eds.), Cls 26-ii: Papers from the parasession on the syllable in phonetics and phonology, 355-398. Chicago: Chicago Linguistic Society.

Prince, Alan \& Paul Smolensky. 1993. Optimality theory: Constraint interaction in generative grammar. Rutgers University Center for Cognitive Science Technical Report 2.

$\mathrm{Qu}$, Chen \& Heather Goad. In progress. On the interaction of tone and stress in contour tone languages: A prosodic account .

Selkirk, Elisabeth O. 1984. Phonology and syntax: The relation between sound and structure. Cambridge, MA: MIT Press.

Stewart, John. 1965. The typology of the twi tone system. Bulletin of the Institute of African Studies 1. 1-27.

Urua, Eno-Abasi. 1999. Length and syllable weight in ibibio. Studies in African Linguistics 28(2). 241-266.

Voorhoeve, Jan. 1971. Tone in Bamileke. Language 1(5). 45.

Yip, Moira. 1989. Contour tones. Phonology 6(1). 149-174.

Yu, Alan. 2010. Tonal effects on perceived vowel duration. Laborabory Phonology(10).

Zhang, Jie. 2002. The effects of duration and sonority on contour tone distribution-typological survey and formal analysis: UCLA dissertation.

Zhang, Jie. 2004. The role of contrast-specific and language-specific phonetics in contour tone distribution. In Bruce Hayes, Robert Kirchner \& Donca Steriade (eds.), Phonetically based phonology, 157-190. Cambridge, MA: Cambridge University Press. 